\title{
O DESENVOLVIMENTO URBANO SUSTENTÁ VEL E OS TRATADOS INTERNACIONAIS SOBRE MUDANÇAS CLIMÁTICAS
}

\author{
Karen Bissani \\ Universidade Comunitária da Região de Chapecó - \\ UNOCHAPECÓ, Santa Catarina \\ Reginaldo Pereira \\ Universidade Comunitária da Região de Chapecó - \\ UNOCHAPECÓ, Santa Catarina
}

\begin{abstract}
RESUMO: O presente trabalho trata das relações entre o desenvolvimento e o planejamento urbano sustentável com base nas diretrizes definidas por documentos internacionais sobre mudanças climáticas. $\mathrm{O}$ artigo parte da hipótese de que o desenvolvimento urbano sustentável deveria ser uma diretriz definidora de políticas públicas e de modelos de governança voltados à proteção dos vulneráveis, que são os primeiros a sentir os impactos causados pelas mudanças climáticas. A preocupação da comunidade internacional com o tema é demonstrada a partir da Convenção-Quadro das Nações Unidas sobre Mudança do Clima (UNFCCC) de 1992, que buscou um padrão de crescimento econômico e social aliado à preservação ambiental e ao equilíbrio climático em todo o planeta. Na sequência o Protocolo de Kyoto de 1997 e o Acordo de Paris de 2015, que deram uma nova dinâmica ao processo de constitucionalização do regime jurídico internacional climático. Assim, a Agenda 2030 da Organização das Nações Unidas (ONU) de 2015, que dentre os 17 Objetivos Globais para o Desenvolvimento Sustentável dedicou o objetivo número 13 à necessidade da adoção de medidas urgentes para a reversão das mudanças do clima e mitigação de seus impactos. Por fim, analisam-se as propostas apresentadas pelo governo brasileiro frente ao Acordo de Paris e quais as ações políticas foram implementadas para dar cumprimento aos compromissos assumidos pelo país nos tratados internacionais sobre mudanças climáticas. A pesquisa é analítica e o método utilizado é o descritivo, com base em pesquisa bibliográfica realizada em meios impresso e digital.
\end{abstract}

PALAVRAS-CHAVE: Acordos Internacionais Sobre Mudanças Climáticas. Desenvolvimento Urbano Sustentável. Governança.

\section{Sustainable Urban Development and International Treaties on Climate Change}

ABSTRACT: This paper deals with the relationship between development and sustainable urban planning based on the guidelines defined by international documents on climate change. The article starts from the hypothesis that sustainable urban development should be a defining guideline of public policies and governance models aimed at protecting the vulnerable, who are the first to feel the impacts caused by climate change. The international community's concern with the issue is demonstrated by the 1992 United Nations Framework Convention on Climate Change (UNFCCC), which sought a pattern of economic and social growth coupled with environmental preservation and climate balance around the globe. Following the Kyoto Protocol of 1997 and the Paris Agreement of 2015, which gave a new impetus to the process of constitutionalization of the international climate legal regime. Thus, the United Nations (UN) Agenda 2030, which among the 17 Global Objectives for Sustainable Development, dedicated the objective number 
13 to the need to adopt urgent measures to reverse climate change and mitigate its impacts. Finally, we analyze the proposals presented by the Brazilian government regarding the Paris Agreement and what political actions were implemented to comply with the commitments made by the country in the international treaties on climate change. The research is analytical and the method used is descriptive, based on bibliographical research carried out in print and digital media.

KEYWORDS: International Agreements on Climate Change. Sustainable Urban Development. Governance.

\section{INTRODUÇÃO}

Nas últimas décadas o desenvolvimento econômico mundial tem caminhado a passos largos, causando significativos efeitos na relação entre o ser humano e o meio ambiente. $O$ grande desafio é unir o crescimento econômico com o desenvolvimento sustentável tratando o planejamento urbano e a preservação do meio ambiente de forma solidária, como políticas públicas que atuem efetivamente nas relações sociais.

No Brasil, os fundamentos da valorização do trabalho humano e da livre iniciativa, contidos na Constituição Federal de 1988, foram concebidos para assegurar à todos uma existência digna, segundo os ditames da justiça social. Porém, em um país de dimensões continentais, com um histórico de milhões de pessoas vivendo abaixo da linha da pobreza, as questões urbanísticaambientais acabam sendo colocadas em segundo plano, e a solução de problemas imediatos como os de subsistência acabam tendo prioridade.

Dado o contexto atual a perspectiva apresentada neste estudo é como o desenvolvimento urbano sustentável, aplicado através de políticas públicas voltadas ao ordenamento do uso e a ocupação do solo de forma eficiente, poderia proteger a população e o meio ambiente dos impactos das mudanças climáticas.

A pesquisa pretende demonstrar que o desenvolvimento urbano sustentável, se tratado como como diretriz central de políticas públicas e de modelos de governança voltados à proteção dos vulneráveis, poderia amenizar os impactos causados pelas mudanças climáticas, visto que estes são os primeiros a senti-los. Quer ainda demonstrar quais as ações políticas foram implementadas para dar cumprimento aos compromissos assumidos pelo Brasil nos tratados internacionais sobre mudanças climáticas.

O Estado tem o dever de promover o bem-estar social apresentando instrumentos institucionais que resolvam os conflitos, reconhecendo as necessidades coletivas com planejamento adequado, permitindo o desenvolvimento sustentável sob quatro dimensões, quais sejam: econômica, social, ambiental e institucional.

Para grande parte da comunidade internacional a preocupação com as mudanças climáticas ganhou novos contornos a partir de acordos internacionais como o Acordo de Paris sobre Mudanças Climáticas firmado em 2015, cujo objetivo central é fortalecer a resposta global à ameaça da mudança do clima e reforçar a capacidade dos países para lidar com os impactos decorrentes dessas mudanças. 


\section{A PROTEÇÃO DO MEIO AMBIENTE E O DESENVOLVIMENTO ECONÔMICO}

A Política Nacional de Meio Ambiente foi estabelecida no Brasil pela Lei Federal $n^{\circ}$ 6.938 de 31 de agosto de 1981, trazendo instrumentos e diretrizes para orientar ações governamentais. O objetivo geral, expresso no caput do artigo $2^{\circ}$, trata da preservação, melhoria e recuperação da qualidade ambiental indispensável à vida, visando assegurar condições para o desenvolvimento socioeconômico, os interesses da segurança nacional e à proteção da dignidade da vida humana (BRASIL, 1981).

A partir da sua aprovação, o país passou a ter um marco legal que transpassava todas as políticas públicas de meio ambiente a serem desenvolvidas pelos entes federativos. Antes disso, cada Estado ou Município tinha autonomia para eleger as suas diretrizes políticas em relação ao meio ambiente de forma independente, embora na prática poucos realmente demonstrassem interesse pela matéria (FARIAS, 2008).

Na sequência, a Constituição Federal de 1988 elencou no caput do artigo 225, o direito que todos têm ao meio ambiente ecologicamente equilibrado, sendo essencial à sadia qualidade de vida, atribuindo ao Poder Público e a coletividade o dever de defendê-lo e preservá-lo para às presentes e futuras gerações. Nota-se que o texto constitucional buscou harmonizar os dispositivos voltados à ordem econômica e à proteção ambiental, tratando o direito ao meio ambiente ecologicamente equilibrado como um direito social (BRASIL, 1988).

Para José Afonso da Silva (2004) a qualidade do meio ambiente transformou-se num bem ou patrimônio cuja preservação, recuperação ou revitalização se tornaram um imperativo do Poder Público para assegurar a qualidade de vida, e que implicaria em boas condições de trabalho, lazer, educação, saúde e segurança. Ainda segundo o autor, o desenvolvimento econômico e a proteção ao meio ambiente seriam dois valores aparentemente em conflito na Constituição Federal de 1988, o que poderia influenciar no bem-estar e na boa qualidade de vida dos brasileiros

Muito embora a proteção ambiental no Brasil tenha se modificado com o passar dos anos, e certamente as inúmeras discussões mundiais sobre o assunto ajudaram muito para que isso acontecesse, a preocupação em unir desenvolvimento econômico e políticas de sustentabilidade ainda encontra muita resistência, além do que não existe um maciço investimento público na recuperação e conservação ambiental, assim como existem poucas empresas realmente comprometidas com a preservação da natureza. O fato é que o desenvolvimento econômico aliado ao desenvolvimento científico, na maioria das vezes, vem acompanhado da degradação ambiental, demonstrando que nem sempre as questões ambientais são colocadas em primeiro lugar, o que permite que a eterna busca pelo lucro cause a escassez de muitos recursos naturais.

Nesse sentido, ao discutir diversos dispositivos contidos no Código Florestal Brasileiro, a Lei Federal n ${ }^{\circ} 12.651 / 2012$, o Supremo Tribunal Federal manifestou-se quanto a necessidade de se encerrar o aparente conflito normativo entre a proteção ao meio ambiente e o desenvolvimento econômico, envolvendo especialmente a justiça intergeracional. Para o relator Ministro Luiz Fux, a preservação do meio ambiente não significa que não haverá impacto do homem na natureza, contudo, seria possível gerar desenvolvimento econômico assegurando a manutenção de recursos naturais suficientes para os nossos descendentes (BRASIL, 2018).

O Estatuto da Metrópole, instituído pela Lei Federal nº 13.089 de 12 de janeiro de 2015, trata da governança interfederativa das regiões metropolitanas e das aglomerações urbanas, sendo que em seu artigo $6^{\circ}$, inciso VII, apresenta entre outros, a busca do desenvolvimento sustentável como princípio (BRASIL, 2015). Além do que, a ordem econômica nacional também é regida por princípios trazidos pela Constituição Federal de 1988, sendo que em seu artigo 170 
enumera a defesa do meio ambiente, inclusive mediante tratamento diferenciado conforme o impacto ambiental dos produtos e serviços e de seus processos de elaboração e prestação (BRASIL, 1988).

Assim, a atividade econômica, diferentemente do ocorria no passado, como meio de subsistência industrial, segue a tendência de diminuir os impactos causados ao meio ambiente pela prática extrativista desenfreada. Com a inserção da defesa ao meio ambiente como princípio de ordem econômica, o constituinte estabeleceu que é do Estado a responsabilidade pelo desenvolvimento de políticas públicas visando o uso consciente e a preservação ambiental (SZEZERBICKI, 1988).

Para Henri Lefebvre (2011) não é possível considerar separadamente industrialização e a urbanização, mas perceber na urbanização o sentido, o objetivo ou a finalidade da industrialização, ou seja, não se pode visar somente o crescimento econômico, sendo necessário buscar o equilíbrio econômico, o crescimento harmonioso subordinado a conceitos mais amplos de desenvolvimento, de racionalidade onde emergem os conflitos.

Na verdade, o que se almeja é o desenvolvimento sustentável, ou seja, aquele que é viável economicamente, justo socialmente e correto ambientalmente, e que leve em consideração não só as necessidades atuais, mas também as das gerações futuras, tanto nas comunidades em que vivemos quanto no planeta como um todo (FOLTZ 2008).

\section{AS CONSEQUÊNCIAS SOCIOAMBIENTAIS DA AUSÊNCIA DE PLANEJAMENTO URBANO}

A expansão urbana no Brasil vem acontecendo de forma desestruturada há muitas décadas, o que tem gerado inúmeros problemas urbanísticos, ambientais e sociais, frutos da descontinuidade de políticas públicas, ou ausência delas, e que não priorizam um efetivo planejamento urbano.

A globalização dos mercados e aumento das exportações elevaram os índices produtivos das indústrias, gerando mais renda e atraindo os moradores de zonas rurais às grandes metrópoles. Esse inchaço das cidades fez que surgissem, entre outros motivos, dezenas ou milhares de parcelamentos do solo clandestinos ou irregulares. Os reflexos são visíveis, tanto em municípios pequenos como em grandes metrópoles, onde a maior parte da população vive sem acesso à serviços públicos, sem infraestrutura básica, ou seja, não recebe um tratamento digno.

Nesse contexto, muitos brasileiros são forçados a construir suas residências de maneira irregular em áreas de risco, sem as condições mínimas de estrutura urbana (drenagem, pavimentação, esgoto sanitário), ficam vulneráveis às enchentes, deslizamentos e demais intempéries da natureza. Não é raro que essas construções acabem sendo erguidas em Áreas de Preservação Permanente, áreas originalmente destinadas à proteção do meio ambiente e que não deveriam sofrer a intervenção humana (AQUINO; FARIAS, 2017). Surge, então, uma complexa questão para a consolidação de uma justiça ambiental, a busca pela compatibilização entre os direitos sociais e ambientais.

Uma política de desenvolvimento urbano, entre outros objetivos, deve garantir condições de urbanização adequada e proporcional ao crescimento sócio espacial da cidade, mas na realidade a maioria dos municípios brasileiros tem dificuldade com a gestão e o planejamento territorial especialmente por falta de recursos financeiros. 
O crescimento urbano desordenado reflete diretamente na vida da população. No caso do direito à moradia as consequências são ainda mais graves. A falta de moradia prejudica o acesso às políticas públicas; a inserção no mercado de trabalho; a obtenção de crédito, ou seja, o cidadão fica impedido de exercer seus direitos sociais caso não tenha uma moradia adequada (AQUINO; FARIAS, 2017).

A ausência de investimentos em habitação de interesse social empurra a população com poucas condições financeiras de adquirir um imóvel na chamada "cidade formal", para áreas sem valor comercial ou áreas com restrições de construção como Áreas de Preservação Permanente ou áreas de risco, suscetíveis a inundações e desastres naturais.

Os lotes que cumprem a legislação urbanística, assim como os financiamentos que a política de crédito imobiliário disponibiliza estão reservados a um círculo restrito. Para a maioria, sobram os mercados informais e irregulares, ou seja, lotes em que a legislação urbanística e ambiental impede a construção ou não disponibilizou para o mercado formal em espaços precários das periferias distantes da cidade (ROLNIK, 2009).

Não basta existirem leis e dispositivos administrativos que facultem ao Poder Público intervir e chamar para si a responsabilidade de ordenar e regular a ocupação da propriedade urbana se não se implementam políticas públicas dirigidas e orientadas, e se dessa gestão não resultam efeitos práticos permaneceremos carentes de qualquer diretriz sistemática quanto ao urbanismo das cidades (CARDOSO, 1991).

É preciso que sejam mencionados justamente os impactos ambientais causados por essas ocupações, tanto para o meio ambiente quanto para a população que vive nestas condições. Existe a necessidade de legitimar e legalizar as áreas ocupadas por moradias, buscando-se garantir a permanência das famílias nas áreas ocupadas, contudo, desde que não haja risco para os seus moradores.

\section{O DESENVOLVIMENTO URBANO SUSTENTÁVEL}

O conceito de desenvolvimento sustentável surgiu a partir de estudos da Comissão Mundial para o Meio Ambiente e o Desenvolvimento (CMMAD), formada pela Organização das Nações Unidas (ONU) e também chamada de Comissão de Brundtland, apresentados na Conferência das Nações Unidas realizada no Rio de Janeiro em 1992, a "Rio 92". O relatório ficou conhecido como Relatório Brundtland e trouxe uma das definições mais difundidas do termo "desenvolvimento sustentável", sendo descrito como aquele que atende as necessidades do presente sem comprometer as possibilidades de as gerações futuras atenderem suas próprias necessidades (BARBOSA, 2008).

O Relatório Brundtland expressou, pela primeira vez num organismo internacional, o desejo de que o desenvolvimento seja de fato sustentável, ou seja, significa que o crescimento econômico deveria respeitar os limites da natureza, ao invés de destruí-la. O slogan "desenvolvimento sustentável" na forma descrita no documento foi um importante avanço naquele momento, no entanto, significava apenas um ponto de partida para um debate que pudesse culminar em ações concretas (VEIGA, 2008).

Em que pese ter recebido inúmeras críticas, o relatório acabou chamando a atenção do mundo para os problemas ambientais, demonstrando que a possibilidade de desenvolvimento sustentável está intrinsecamente ligada à erradicação da pobreza e da satisfação de necessidades básicas como alimentação, saúde e moradia. 
Na maioria dos países em desenvolvimento percebe-se que o crescimento econômico influencia diretamente no adensamento urbano, por este motivo o planejamento dos espaços físicos das cidades bem como a própria concepção de propriedade urbana merece maior atenção dos poderes estatais.

Uma gestão pública urbana de qualidade deveria considerar a ideia de desenvolvimento sustentável, especialmente em virtude dos inúmeros problemas que afetam as cidades, como é o caso do saneamento ambiental e das ocupações irregulares. Se o desenvolvimento sustentável realmente fosse aplicado, a propriedade e o meio ambiente estariam em harmonia no espaço urbano, uma vez que haveria a utilização racional e sustentável dos recursos naturais dentro das cidades (OLIVEIRA; BESSA, 2005).

A natureza e as características dos problemas ambientais atuais tais como o aquecimento global, perda da biodiversidade, entre outros, requer uma abordagem mais robusta da sustentabilidade e, de certa forma, condiciona a noção de cidade sustentável, atrelando-o, primeiramente, ao elemento ecológico, por ser a base dos demais (PEREIRA; BISSANI, 2017).

Os instrumentos legais existem, a Constituição Federal de 1988 avançou nesse sentindo e previu um capítulo específico sobre a política urbana (artigos 182 e 183) e que posteriormente foram regulamentados pela Lei Federal no 10.257/2001, o Estatuto da Cidade, um verdadeiro marco regulatório da gestão territorial brasileira, que tem como objetivo principal dotar os municípios de maior autonomia para controlar os processos de urbanização com a aplicação de instrumentos dando suporte ao enfrentamento das questões urbanas que afetam a vida da população (BRASIL, 2001).

A aprovação do Estatuto da Cidade inegavelmente consolidou a ordem constitucional no Brasil quanto ao controle dos processos de desenvolvimento urbano, visando reorientar a ação do Estado, dos mercados imobiliários e de toda a sociedade, de acordo com novos critérios econômicos, sociais e ambientais (FERNANDES, 2010).

Para Raquel Rolnik (2007) o Estatuto da Cidade abarca um conjunto de princípios, no qual está expressa uma concepção de cidade e de planejamento e gestão urbana, bem como uma série de instrumentos que são meios para atingir as finalidades desejadas, delegando a cada um dos municípios, a partir de um processo público e democrático, a declaração de suas prioridades.

O grande desafio dos gestores públicos é, sem dúvida nenhuma, equilibrar o crescimento econômico e a conservação ambiental. Desafio este que têm a ver com a destruição ou perda de recursos naturais tais como, o habitat das espécies, as florestas, os solos, os estoques de peixes, sendo que todos dizem respeito aos limites da natureza. Assim, percebe-se que em matéria ambiental não há soluções simples e as discussões, de fato, vêm se aprofundando desde então, suscitando encontros e compromissos internacionais como as conferências Rio-92, Rio+10 e o Protocolo de Kyoto (VEIGA, 2008).

Segundo Ignacy Sachs (2010) em sua consagrada obra "Caminhos para o desenvolvimento sustentável" referindo-se aos debates e encontros mundiais sobre meio ambiente desenvolvimento sustentável, defende o desenvolvimento social atrelado as questões ambientais e alerta sobre a necessidade de policiarmos nossas ações que produzem efeitos negativos ao planeta, salientando a importância de se pensar em um crescimento econômico que vise a proteção da biodiversidade. 


\section{A AGENDA 2030 PARA O DESENVOLVIMENTO SUSTENTÁVEL}

$\mathrm{Na}$ esfera internacional existe uma grande preocupação com o equilíbrio entre as relações humanas e o meio ambiente, através do desenvolvimento sustentável e do respeito aos direitos diretamente vinculados à fonte de todos os valores, qual seja o valor da pessoa humana e sua dignidade.

Em 2015, foi adotada uma nova agenda para o desenvolvimento sustentável, baseada nos oito Objetivos de Desenvolvimento do Milênio (ODM). Essa agenda, lançada na Cúpula de Desenvolvimento Sustentável, em Nova Iorque, foi discutida na Assembleia Geral das Organizações das Nações Unidas, onde os Estados-membros e a sociedade civil puderam apresentar suas contribuições (ONU, 2015).

A Agenda 2030 foi ratificada por Estados dentro de uma organização internacional e apresenta os sujeitos domésticos que irão programar ações, trazendo o âmbito local para o campo das relações internacionais. Assim, concede-lhes relevância na aplicação e concretização de seus objetivos, especialmente por focar nele as políticas de desenvolvimento sustentável. Ao analisarmos sua evolução histórica, bem como a evolução das relações internacionais, vemos que as teorias sobre as relações internacionais e desenvolvimento sustentável acompanham a evolução global, buscando estar atualizadas e em consonância com o cenário que refletem, para servirem aos seus propósitos (CARVALHO, 2018).

Também conhecido como Metas Globais, os 17 Objetivos de Desenvolvimento Sustentável os ODS foram construídos sobre o legado dos Objetivos de Desenvolvimento do Milênio (ODM) e concluirão o que estes não conseguiram alcançar anteriormente. Buscam concretizar os direitos humanos de todos, sendo integrados e indivisíveis, e pretendem equilibrar as três dimensões do desenvolvimento sustentável: a econômica, a social e a ambiental para os próximos 15 anos em áreas de importância crucial para a humanidade (ONU, 2017).

Os Objetivos de Desenvolvimento Sustentável (ODS) são uma ideia importante e podem ajudar a mover o mundo para uma trajetória sustentável. Ganharam rapidamente terreno devido à crescente urgência do desenvolvimento sustentável para o mundo inteiro. Embora as definições específicas possam variar, o desenvolvimento sustentável abrange a chamada abordagem de linha de base tripla para o bem-estar humano. Quase todas as sociedades do mundo reconhecem que visam uma combinação de desenvolvimento econômico, sustentabilidade ambiental e inclusão social (SACHS, 2012).

O crescimento econômico global agora liderado pelas economias emergentes está colocando uma pressão sem precedentes nos ecossistemas da Terra. A humanidade enfrenta não apenas uma, mas muitas crises sobrepostas de sustentabilidade ambiental, incluindo: mudanças climáticas como resultado de emissões de gases de efeito estufa causadas pelo homem; poluição ambiental maciça, além das ameaças ambientais, a humanidade enfrenta graves ameaças que fazem parte da agenda de desenvolvimento sustentável (ONU, 2015).

Entre os 17 Objetivos de Desenvolvimento Sustentável (ODS) destaca-se o Objetivo ${ }^{\circ}$ 13, que trata da necessidade de serem tomadas medidas urgentes para combater as mudanças do clima e seus impactos. Isso acontece porque as mudanças climáticas já afetam todos os países em todos os continentes, trazendo impactos negativos na economia e na vida das pessoas, e no futuro, as consequências serão ainda piores.

A mudança climática é um desafio global que não respeita as fronteiras nacionais. As pessoas sentem na própria pele as consequências das mudanças climáticas, que incluem mudanças nos padrões climáticos, aumento do nível do mar e os eventos climáticos mais extremos. As 
emissões de gases de efeito estufa causadas pelas atividades humanas fazem com que essa ameaça aumente. Na verdade, as emissões nunca foram tão altas. Se não forem tomadas providências, a temperatura média da superfície do mundo poderia aumentar em três graus centígrados neste século e em algumas áreas do planeta poderia ser ainda pior. As pessoas mais pobres e vulneráveis serão as mais afetadas (ONU, 2016).

\section{OS IMPACTOS DAS MUDANÇAS CLIMÁTICAS E O ORDENAMENTO DO USO E OCUPAÇÃO DO SOLO}

Para Bastiaan Philip Reydon (2007), parte significativa dos problemas de uso e ocupação do solo rural e urbano no Brasil, decorre da falta de regulação adequada destes mercados. Porquanto, a regulação ideal seria aquela na qual a sociedade pudesse definir o uso adequado do solo quer do ponto de vista produtivo, quer para habitações, preservando simultaneamente o meio ambiente. Daí a necessidade de se pensar em políticas públicas que possibilitem regular a forma de ocupação e o uso do solo, fazendo com que o mercado deixe de ser movido pela especulação, e passe a buscar a melhoria social e ambiental.

A criação das Áreas de Preservação Permanente (APP's) pelo Código Florestal Brasileiro de 1965 tinha como objetivo proteger a flora, a fauna, os recursos hídricos de maneira a garantir o equilíbrio do meio ambiente e a consequente manutenção da vida humana com qualidade, deixando estas áreas a salvo do desenvolvimento econômico e da degradação (FARIAS, 2003).

Contudo, muitas áreas ambientalmente protegidas estão fisicamente ocupadas e apesar da existência de legislação para regular o acesso à terra, estas são normalmente ambíguas ou permitem o não cumprimento impune, o que sempre beneficia os especuladores e os grileiros de terras em detrimento do seu melhor uso coletivo (REYDON; GUEDES, 2012).

A luta contra a mudança climática se tornou um dos grandes desafios da atualidade, isso porque afeta diversos setores essenciais para o desenvolvimento da vida social, exigindo, assim, a implementação de estruturas de governança que respondam adequadamente aos efeitos adversos de tal fenômeno. Para que as APP's cumpram sua função na mitigação das mudanças climáticas é fundamental que a legislação ambiental atual se fortaleça no sentido de ampliar sua proteção e garantir a redução dos efeitos do desmatamento de florestas e outras formas de vegetação, gerando um ciclo virtuoso que permita ao nosso país a ampliação das políticas de proteção florestal (CONTIPELLI; MACIEL).

As mudanças climáticas estariam entre um dos "problemas sem passaporte", como bem definido por Kofi Annan, ex-secretário geral da ONU, isto é, questões que só podem ser tratadas ultrapassando fronteiras, ou seja, problemas que não pertencem a esta nação ou a essa nação, mas ao mundo inteiro, exigindo esforços cooperativos em nível global, para encontrar suas soluções. As mudanças climáticas são hoje, um dos maiores desafios da sociedade, demandando ampla cooperação internacional para engajar nações e outros atores internacionais na implementação da governança global, a fim de buscar soluções comuns para esse problema ambiental que afetam todos (CONTIPELLI, 2017).

Neste sentido o desenvolvimento urbano sustentável, se bem aplicado, poderia servir de instrumento para proteger a população e o meio ambiente dos impactos das mudanças climáticas, desde que executado através de políticas públicas voltadas ao ordenamento do uso e a ocupação do solo que priorizasse a eficiência deste, prevenindo e desestimulando a criação de ocupações irregulares. 
Atualmente, a tendência é ampliar a compreensão de que a terra constitui uma importante questão de governança, especialmente no enfretamento de desafios complexos como as mudanças climáticas, a aceleração da urbanização, o aumento na demanda por recursos naturais, a insegurança alimentar, hídrica e energética, catástrofes naturais e conflitos agrários violentos. Muitos desses desafios têm uma dimensão claramente relacionada com a terra: o acesso desigual a terra, a insegurança jurídica dos posseiros, o uso insustentável da terra e instituições débeis para a governança territorial e a resolução de disputas e conflitos (FAO, 2017).

Nas cidades, a população mais vulnerável aos desastres socioambientais é a população de baixa renda, desassistida pelo poder público, devido à omissão do Estado na execução de uma política habitacional consistente. Esta vulnerabilidade significa menor capacidade de evitar os desastres e também menor capacidade de resistir e reagir após sua ocorrência (SIEBERT, 2012).

\section{O COMPROMETIMENTO do BRASIL COM O ACORdo DE PARIS SOBRE O CLIMA}

A preocupação com as questões ambientais vem aumentando progressivamente a nível mundial, assim como a busca por soluções que possam atuar os efeitos das mudanças climáticas. Da mesma forma como maioria dos problemas ambientais contemporâneos, os impactos das mudanças climáticas se espalham além das fronteiras dos países e somado ao caráter intergeracional do problema, as soluções implicam em decisões de ordem interestatal (SOUZA, 2017).

O Acordo de Paris sobre mudanças climáticas foi negociado em 2015, consistindo em uma perspectiva para ações efetivas envolvendo várias nações, e serviu para traçar o caminho para um mundo sustentável através de mudanças na economia global. Além disso, este Acordo propôs um conjunto de ações e investimentos para reforçar a capacidade dos países de lidar com o impacto das mudanças climáticas.

Sobre a efetividade das ações propostas é importante destacar que os Estados Unidos se uniu à China para ratificar formalmente o pacto, demonstrando o compromisso assumido pelas duas maiores economias do mundo, que representam $40 \%$ do total mundial de emissão de gases de efeito estufa, para cooperar em ações ambientais e para fortalecer sua liderança na construção de uma estrutura climática internacional (CONTIPELLI, 2017).

O regime climático, como se sabe, fundamenta-se no princípio da responsabilidade comum, porém diferenciada, entre os países, e que visa distribuir com equidade a parcela de ônus, de obrigações que cada país deve suportar nas ações de mitigação, e na sua capacidade interna de adaptação. O Brasil, ocupou papel destacado e de liderança no primeiro período de negociações do regime, contudo, parece ter perdido seu protagonismo durante os últimos anos, ficando à margem das grandes decisões e articulações, em virtude da perda de prioridade da agenda ambiental pelo governo federal (REI; GONÇALVES; SOUZA, 2017).

O entendimento da maioria dos especialistas em mudanças climática é de que o sucesso do Acordo de Paris depende de cada um dos países signatários e suas políticas públicas ambientais. As metas fixadas, se cumpridas, poderiam barrar o aquecimento global até o fim do século, mas os retrocessos dos últimos anos, seja por conta das colocações políticas dos Estados Unidos ou do governo brasileiro, torna cada vez mais difícil colocar a humanidade em um caminho de segurança climática. 


\section{CONCLUSÃo}

A ocupação de áreas ambientalmente protegidas é um problema que atinge a maioria dos municípios brasileiros, para o meio ambiente a perda é grande, pois as ocupações irregulares em Área de Preservação Permanente urbanas acarretam prejuízos decorrentes da poluição nos rios, deslizamentos, inundações além da destruição de áreas que deveriam ser preservadas.

Percebe-se então a necessidade de um novo padrão de desenvolvimento urbano, pois o controle e a organização do processo de urbanização somente serão alcançados através de um eficiente planejamento urbano e uma gestão municipal democrática participativa, que assegure o crescimento sustentável das cidades.

Os Objetivos de Desenvolvimento Sustentável da ONU são um pacote de prioridades que tem como finalidade contribuir para a promoção e melhoria de políticas públicas, fortalecendo a troca de experiências e a pressão sobre os governos para seu cumprimento. Embora muitos avanços tenham sido registrados desde a adoção destes objetivos, ainda há um longo caminho a percorrer rumo a um mundo mais justo e inclusivo.

Por fim, conclui-se pela importância da compreensão de que as cidades não são apenas vítimas dos efeitos das mudanças climáticas, mas são o resultado das escolhas dos nossos governantes, ou seja, de alguma forma somos corresponsáveis pelo agravamento dos problemas, já que os seus impactos são consequência de um desenvolvimento urbano insustentável do ponto de vista ambiental. Somente a aceitação dos limites naturais e um desenvolvimento urbano planejado de forma sustentável nos permitirá adaptar as cidades para torná-las menos vulneráveis aos desastres ambientais.

\section{REFERÊNCIAS}

AQUINO, Vinicius Salomão de; FARIAS, Talden. Regularização Fundiária em Áreas de Preservação Permanente sob a Perspectiva da Sustentabilidade Socioambiental. Editora da UFPB, 2017.

BARBOSA, Gisele Silva. O desafio do desenvolvimento sustentável. Revista Visões $4^{\text {a }}$ Edição, No 4, Volume 1 - Jan/Jun. 2008.

BRASIL, 1981. Lei Federal n⿳0 6.938 de 31 de agosto de 1981. Dispõe sobre a Política Nacional do Meio Ambiente, seus fins e mecanismos de formulação e aplicação, e dá outras providências. Disponível em: http://www.planalto.gov.br/ccivil_03/leis/16938.htm. Acesso em: 22 maio 2018.

BRASIL, 1988. Constituição Federal de 1988. Disponível em: https://www2.camara.leg.br/legin/fed/consti/1988/constituicao-1988-5-outubro-1988-322142-publicacaooriginal-1-pl.html.

Acesso em: 22 maio 2018.

BRASIL, 2001. Lei Federal $n^{0}$ 10.257/2001. Regulamenta os arts. 182 e 183 da Constituição Federal, estabelece diretrizes gerais da política urbana, e dá outras providências. Disponível em: http://www.planalto.gov.br/ccivil_03/leis/leis_2001/110257.htm. Acesso em: 22 maio 2018.

BRASIL, 2015. Lei Federal $\mathbf{n}^{\mathbf{0}} \mathbf{1 3 . 0 8 9}$ de 12 de janeiro de 2015. Institui o Estatuto da Metrópole, altera a Lei $\mathbf{n}^{\mathbf{0}} \mathbf{1 0 . 2 5 7}$, de 10 de julho de 2001, e dá outras providências. Disponível em: http://www.planalto.gov.br/ccivil_03/_ato2015-2018/2015/lei/113089.htm. Acesso em: 22 maio 2018. 
BRASIL, 2018. Superior Tribunal de Justiça. 2018. Recurso Especial no 586.224/SP. ADC 42/ DF, rel. Min. Luiz Fux, julgamento em 28.2.2018. Disponível em: http://www.stf.jus.br/portal/ informativo/verInformativo.asp?s1=desenvolvimento+prox+sustentavel\&pagina $=1 \&$ base $=$ INFO. Acesso em: 22 maio 2018.

CARDOSO, Adauto. A utopia em construção: modernidade, ecologia e urbanização. In Brazil: território da desigualdade. Rio de Janeiro: Jorge Zahar, 1991.

CARVAlHO, Francisco Toniolo de Carvalho. A Agenda 2030 para o Desenvolvimento Sustentável da ONU e seus atores: o impacto do desenvolvimento sustentável nas relações internacionais. Disponível em: http://www.academia.edu/34664468. Acesso em: 20 out. 2018

CONTIPELLI, Ernani e MACIEL, Marjara Garcez. REDD: Marcos Financeiros Climáticos e Áreas de Preservação Permanente. Migração, Mudança Climática e Economia Social em um Mundo Globalizado Migração, mudança climática e economia social em um mundo M636 globalizado / [organizado por] Daniel Francisco Nagao Menezes, 2018 Ernani de Paula Contipelli, Luís Renato Vedovato. Belo Horizonte: Arraes Editores, 2018.

CONTIPELLI, Ernani. Trump's Doctrine and Climate Change: New Challenges for Global Governance. May 31, 2017. Disponível em: https://www.indrastra.com/2017/05/PAPERSTrump-s-Doctrine-and-Climate-Change-003-05-2017-0068.html\#axzz5OMPQAlCm. Acesso em: 15 dez. 2018

FAO, Organização das Nações Unidas para Alimentação e a Agricultura. Governança de Terras: Da Teoria à Realidade Brasileira. Brasília, 2017.

FARIAS, Talden Queiroz. A edificação urbana à margem de rios e de outros reservatórios de água em face do código florestal. Fórum de Direito Urbano e Ambiental, Belo Horizonte, v. 2, n. 10, jul. 2003.

FARIAS, Talden Queiroz. Aspectos gerais da política nacional do meio ambiente - comentários sobre a Lei $\mathbf{n}^{\mathbf{0}}$ 6.938/81. Universidade Federal de Santa Catarina, 2008 Disponível em: http://www.egov.ufsc.br/portal/sites/default/files/anexos/26875-26877-1-PB.pdf. Acesso em: 15 dez. 2018

FERNANDES, Edesio. O Estatuto da Cidade e a ordem jurídico-urbanística. In: CITIES ALLIANCE; MINISTÉRIO DAS CIDADES (org.). O Estatuto da Cidade comentado. Brasília: Ministério das Cidades, 2010.

FOLTZ, Ana Paula. A crise ambiental e o desenvolvimento sustentável: o crescimento econômico e o meio ambiente. Universidade Federal do Rio Grande do Sul, 2008. Disponível em: http://www.egov.ufsc.br/portal/sites/default/files/anexos/29869-29885--PB.pdf. Acesso em: 24 abr. 2019.

LEFEBVRE, Henri. O Direito à cidade. 5a . Ed. São Paulo: Centauro, 2011.

OLIVEIRA, Cleide de; BESSA, Fabiane Bueno Lopes Netto. Estatuto da Cidade e Desenvolvimento Sustentável: Necessidade de Plano Diretor para Municípios com menos de vinte mil habitantes. CONPEDI, 2005. Disponível em: http://www.publicadireito.com.br/conpedi/ manaus/arquivos/anais/salvador/fabiane_bueno_lopes_netto_bessa.pdf. Acesso em: 24 abr. 2019.

ONU. Assembleia Geral das Nações Unidas. Os 17 Objetivos de Desenvolvimento Sustentável da ONU. Atualizado em 12/04/2017. Disponível em: https://nacoesunidas.org/conheca-os-novos-17-objetivos-de-desenvolvimento-sustentavel-da-onu/. Acesso em: 02 maio 2019. 
ONU. Assembleia Geral das Nações Unidas. Transformando Nosso Mundo: A Agenda 2030 para o Desenvolvimento Sustentável. Última edição em 13 de outubro de 2015 Traduzido pelo Centro de Informação das Nações Unidas para o Brasil (UNIC Rio). Disponível em: https:// nacoesunidas.org/pos2015/agenda2030/. Acesso em: 02 maio 2019.

ONU. Organização das Nações Unidas. Objetivo 13: Adoptar medidas urgentes para combatir el cambio climático y sus efectos. Objetivos de desarrollo sostenible, 2016. https:// www.un.org/sustainabledevelopment/es/climate-change-2/. Acesso em: 02 maio 2019.

PEREIRA, Reginaldo; BISSANI, Karen. A Regularização do Parcelamento de Solo de Loteamentos Públicos: Um Estudo Baseado no Projeto do Loteamento de Interesse Social Vila Betinho em Chapecó/SC. Rev. Polít. Públicas (Online), Brasília, v.7, nº 2, 2017.

REI, Fernando Cardozo Fernandes; GONÇALVES, Alcindo Fernandes; SOUZA, Luciano Pereira de. Souza. Acordo de Paris: Reflexões e desafios para o regime internacional de mudanças climáticas. Revista Veredas do Direito. v. 14, n. 29, 2017. Disponível em: http:// dx.doi.org/10.18623/rvd.v14i29.996. Acesso em: 02 maio 2019.

REYDON, Bastiaan Philip e GUEDES, Sebastião Neto Ribeiro. Diretos de Propriedade da Terra Rural no Brasil: uma proposta institucionalista para ampliar a governança fundiária. Rev. Econ. Sociol. Rural vol.50 no 3 Brasília July/Sept. 2012 http://dx.doi.org/10.1590/ S0103-20032012000300008. Acesso em: 02 maio 2019.

REYDON, Bastiaan Philip. A regulação institucional da propriedade da terra no Brasil: uma necessidade urgente. In: RAMOS, P. et. al. Dimensões do agronegócio brasileiro: políticas, instituições e perspectivas. Brasília: MDA, 2007.

ROLNIK, Raquel. Democracia no fio da navalha: Limites e possibilidades para implementação de uma agenda de reforma urbana no Brasil. Revista Brasileira de Estudos Urbanos e Regionais v. 11, n. 2 2009. Disponível em: http://www.urbanismo.mppr.mp.br/arquivos/File/ 2194063PB.pdf. Acesso em: 02 maio 2019.

ROLNIK, Raquel. Regularização fundiária sustentável - conceitos e diretrizes. Brasília: Ministério das Cidades, 2007.

SACHS, Ignacy. Caminhos para o desenvolvimento sustentável. Coleção Ideias Sustentáveis. Organizadora: Paula Yone Stroh. Rio de Janeiro: Garamond, 2000.

SACHS, Jeffrey D. From Millennium Development Goals to Sustainable Development Goals. Columbia University, 2012. Disponível em: http://www.grips.ac.jp/forum/IzumiOhno/ lectures/2015_Lecture_texts/S16_From-MDGs-to-SDGs-Lancet-June-2012.pdf. Acesso em: 02 maio 2019.

SIEBERT, Claudia. Resiliência Urbana: Planejando as Cidades para Conviver com Fenômenos Climáticos Extremos. Setembro, 2012. Belém/PA.

SILVA. José Afonso da. Direito Ambiental Constitucional. $5^{\text {a }}$ edição. Malheiros Editores. São Paulo, 2004.

SOUZA, Maria Cristina Oliveira; CORAZZA, Rosana Icassatti. Do Protocolo Kyoto ao Acordo de Paris: uma análise das mudanças no regime climático global a partir do estudo da evolução de perfis de emissões de gases de efeito estufa. Sistema Eletrônico de Revistas (SER/UFPR) Vol. 42, Dezembro 2017. 
SZEZERBICKI, Arquimedes da Silva. Os Princípios Gerais da Ordem Econômica Brasileira: Avanços e Efetividade desde a Constituição Federal de 1988. Universidade Tecnológica Federal do Paraná, 1988. Disponível em: http://eptic.com.br/wp-content/uploads/2014/12/ textdisc6.pdf. Acesso em: 02 maio 2019.

VEIGA, José Eli da e ZATZ, Lia. Desenvolvimento sustentável, que bicho é esse? Campinas, SP: Autores Associados, 2008.

Recebido em: 6 maio 2019.

Aceito em: 22 maio 2019. 